\title{
Effect of adjuvant imiquimod $5 \%$ cream on sustained clearance of anogenital warts following laser treatment
}

\author{
U. B. Hoyme1, M. Hagedorn ${ }^{2}$, A.-E. Schindler ${ }^{3}$, P. Schneede ${ }^{4}$, W. Hopfenmüller ${ }^{5}$, \\ K. Schorn ${ }^{6}$ and A. Eul ${ }^{6}$ \\ ${ }^{1}$ Department of Obstetrics and Gynecology, Helios Klinikum Erfurt \\ ${ }^{2}$ Department of Dermatology, Klinikum Darmstadt \\ ${ }^{3}$ Department of Gynecology and Gynecological Oncology, Universitätsklinik Essen \\ ${ }^{4}$ Department of Urology, Universitätsklinik Großhadern, München \\ ${ }^{5}$ Institute of Medical Statisitics, Freie Universität Berlin \\ ${ }^{6} 3 \mathrm{M}$ Medica, Borken, Germany
}

\begin{abstract}
Objectives: Imiquimod is an immune response modifier that has demonstrated a good efficacy and relatively low recurrence rates in comparison to other genital wart treatment modalities. The primary objective of this open-label study was to evaluate the effect on sustained clearance of treated lesions and the safety of patient-applied topical imiquimod after laser therapy of external anogenital warts.
\end{abstract}

Methods: After laser treatment of visible external anogenital warts the ablated region(s) were treated with imiquimod $5 \%$ cream three times/week over 12 weeks beginning when the wound healing process was completed, followed by a six-month treatment-free observation period for the assessment of sustained clearance of treated lesions.

Results: A total of 21 I male and female patients was enrolled in the study. After 12 weeks of treatment, $65.4 \%$ of all patients showed sustained clearance. During the treatment period, 15 patients (7. $1 \%$ of 21 I patients) presented with recurrent warts in the treated areas, and 58 (27.5\%) patients were excluded for other reasons. During the six-month follow-up period, ten additional patients ( $7.3 \%$ of 138 patients) developed wart recurrences. The application of imiquimod $5 \%$ cream was well tolerated. The number of patients with adverse events related to study medication declined from the first month of treatment until the end of the third month. Most frequently, mild to moderate itching, burning, pain and erythema were reported.

Conclusions: After laser therapy and sufficient wound healing, administration of imiquimod $5 \%$ cream three times/week appears to be safe and to reduce the incidence of wart recurrences.

Key words: Immune Response Modifier; Condylomata ACuminata; Recurrences

Anogenital infections with human papillomavirus (HPV) represent the most frequent viral sexually transmitted disease (STD) in young adults worldwide. In the USA about one to two percent of the sexually active population between 15-49 years of age develop anogenital warts as the primary clinical manifestation of HPV infection ${ }^{1}$. Recommended treatments include patient applied topical therapies (imiquimod 5\% cream, podophyllotoxin, interferon (IFN)) and ablative or

Correspondence to: Udo Hoyme MD, Klinikum Erfurt GmbH, Klinik für Frauenheilkunde und Geburtshilfe, Gorkistraße 6, 99084 Erfurt, Germany. E-mail: uhoyme@klinikum-erfurt.de 
cytodestructive methods, which have all shown good to moderate efficacy in removing genital warts ${ }^{2}$. Most of the ablative treatment modalities have the potential to be painful and are awkward for the patient due to anaesthesia or repeated therapeutic interventions to remove the entire wart area. However, the major frustration is considered to be the high incidence of wart recurrences after successful primary treatment. Recurrence rates, which have been documented for ablative methods, vary between $20 \%$ with surgical excision up to $50 \%$ with laser therapy ${ }^{3}$. One reason postulated for frequent wart recurrence is the lack of antiviral activity with most of the recommended therapies. Thus, only the wart itself is physically destroyed, while the latent HPV in the surrounding tissue remain present with the potential of reactivation ${ }^{4}$. Imiquimod and interferon are the only medical treatments available that exhibit an antiviral activity: both drugs have demonstrated lower recurrence rates compared to other therapies ${ }^{3}$. Imiquimod is a more complete and natural approach as it is known to induce several subtypes of IFN- $\alpha$ and IFN- $\gamma$, as well as a variety of cytokines associated with Th1-cell-mediated immunity.

Imiquimod $\quad\left(\right.$ ALDARA $^{\circledR} \quad 5 \%$ cream, $3 \mathrm{M}$ Pharmaceuticals, Borken, Germany), an imidazoquinolinamine derivate, is the first representative of a new class of immune response modifiers with potent antiviral and antitumor activity ${ }^{5,6}$. In the primary treatment of external genital warts, imiquimod 5\% cream, applied three times/week for a maximum of 16 weeks, has been shown to be highly effective and safe $\mathrm{e}^{7-9}$. The recurrence rate in one study, with three times per week dosing and a treatment-free follow-up period of 12 weeks, was as low as $13 \%{ }^{8}$.

It has been hypothesized that recurrence rates after wart ablation may be reduced by an adjuvant IFN therapy, enhancing the patient's immune response to viral infections. However, most study results didn't show consistent beneficial effects with combination therapy ${ }^{10}$. This clinical study was performed to determine whether a combination of laser therapy followed by imiquimod $5 \%$ cream for 12 weeks would reduce the incidence of recurrent warts after laser treatment.

\section{METHODS}

\section{Study design}

This was a phase IIIb, open-labelled, prospective, multicenter study performed in 23 sites around Germany. Investigators were recruited predominantly from university hospitals: dermatology $(n=10)$, obstetrics and gynecology $(n=10)$, urology $(n=2)$ and one center of laser therapy. The primary objective of the study was to evaluate the safety and sustained clearance after laser treatment of anogenital warts as assessed by clinical visual inspection. The safety population included all patients who received at least one dose of study drug. The approval of local ethical committees was obtained prior to starting the study and each patient's written consent was obtained prior to enrollment. The study was conducted in accordance with the Declaration of Helsinki and Good Clinical Practice Guidelines (ICH-GCP).

\section{Patients}

Male and female patients with external anogenital warts aged 18 years or older were eligible for the study. The acetowhite area had to be less than $20 \mathrm{~cm}^{2}$, and warts had to be removed by laser irradiation within three weeks before study enrolment of the individual patient.

Patients were excluded from participation in the study if they had undergone any previous treatment with imiquimod; treatment with IFN, IFN-inducers, immunomodulators, oral antiviral drugs (with exception of oral acyclovir for suppressive or acute therapy), topical antiviral drugs to the wart site, cytotoxic drugs, other investigational drugs, drugs known to have major organ toxicity, chemical and/or surgical wart therapy within four weeks prior to entering the study; or oral corticosteroids, inhaled corticosteroids more than $1000 \mu \mathrm{g} /$ day, or any non-wart therapy to the wart site (within two weeks of initiation visit). Additionally, females pregnant or breast feeding and patients with inflammatory skin conditions or patients who required concomitant topical therapy within the wart area were excluded. Other exclusion criteria were: a history of Bowenoid Papulosis, organ transplantation or any unstable medical condition. 


\section{Treatment schedule and control visits}

During the screening visit all visible external condylomata acuminata (target wart area) were removed by laser treatment. Internal warts (vaginal, cervical, urethral, vesical or intra-anal) were also removed but were not considered baseline warts and were not included in the subsequent evaluation procedures; patients with recurrences of their internal warts were excluded. Patients who were completely cleared of their baseline warts and demonstrated sufficient wound healing, entered the treatment phase within 21 days after laser therapy. They were instructed to apply imiquimod $5 \%$ cream to the ablated target wart area three times/week before bedtime; the cream should remain on the skin for $8 \pm 2$ hours.

During the 12 weeks treatment period, patients returned to the investigator every four weeks for clinical evaluation of recurrent warts in the ablated area or new warts outside the target area, and for safety assessment. Whenever recurrent warts in the target area were observed, the patient discontinued treatment and was withdrawn from the study. All patients who completed 12 weeks of treatment without wart recurrences entered the six-month follow-up phase; at three months and six months follow-up, patients were assessed for recurrent and/or new warts.

\section{Assessment of efficacy and safety parameters}

The primary efficacy parameter was the observed sustained clearance rate of the primarily cleared wart areas due to laser therapy during the 12-week treatment phase with imiquimod 5\% cream and the six-month treatment-free follow-up. The target areas (in $\mathrm{mm}^{2}$ ) were determined before laser treatment by measuring the width and length of each wart or cluster of warts, and taking the product of the two largest perpendicular extensions. Total wart area was the sum of the individual warts, or cluster of warts, and was not to exceed $20 \mathrm{~cm}^{2}$. The locations of baseline wart areas were diagrammed and numbered. Any recurrent warts and new warts outside the target area were added to the diagram during the control visits and clearly documented as recurrent or new warts.

The safety of imiquimod 5\% cream was assessed by evaluation of local skin reactions and adverse events at each control visit. Local skin reactions were assessed by the investigators for erythema, edema, induration, vesicles, erosion, ulceration, excoriation/flaking and scabbing. The severity was rated by the study site staff and separately by the patient on a scale of $0-3$ as being $0=$ none, $1=$ mild, $2=$ moderate or $3=$ severe. Additionally, patients were asked for adverse events like itching, burning and pain (application site reactions). No additional clinical or laboratory tests were performed.

All patients who received study medication were included in the statistical evaluation. With regard to the design of the study, descriptive statistical methods were used to evaluate all data including demographic and anamnestic data, observed sustained clearance, safety parameters, other secondary parameters like patient questionnaire on previous and actual treatment(s) and compliance. Variables were stratified by gender.

\section{RESULTS}

\section{Patient characteristics}

Overall, 217 patients were enrolled in the study in the period January-October 1998, and 211 patients were treated with $5 \%$ imiquimod cream after laser irradiation of their visible anogenital warts. The patients age ranged from 18-81 years, with a median age of 32.8 years. Thirty of the 98 male patients $(30.6 \%)$ were circumcised. Fifty-one of the 113 female patients (45.1\%) used an oral contraceptive and 121 patients (57.3\%; 59 males, 62 females) were current tobacco smokers.

\section{Baseline characteristics of target warts and history of disease}

Female patients presented most frequently with vulvar condylomata acuminata (87.6\%). Male patients presented with warts on the shaft of the penis $(41.8 \%)$ and on the glans penis (19.4\%). Uncircumcised males had warts associated with the foreskin in 24.5\% (external) and 32.7\% (internal surface). The second most common wart location in both male and female patients was the perianal region (47.9\% males, $39.8 \%$ females). The total wart area ranged from 2 to $2050 \mathrm{~mm}^{2}$ with a mean of $427 \mathrm{~mm}^{2}$ in male and $256 \mathrm{~mm}^{2}$ in female 
patients. The mean time elapsed since outbreak of the warts was 15 months. Before the patients could participate in the study, all visible warts were removed by laser treatment; the most frequently used lasers were the $\mathrm{CO}_{2}$-laser (176 cases), followed by Nd:YAG-laser in 24 cases, and others in ten cases.

Before study commenced, patients were asked to complete a questionnaire regarding their opinion of their condition and previous treatment(s), if applicable. Most of the patients $(n=112,53.1 \%)$ reported to have undergone at least one previous treatment, most often ablative; $74.1 \%$ were treated within the last six months, and now presenting with wart recurrences or new warts. Treatment was associated with pain in $75.2 \%$ of cases; only 29 reported a total regression of their warts immediately after treatment, and warts recurred in nearly $40 \%$ of all pretreated patients. Details on previous treatments and patient experiences are given in Table 1.

\section{Patient accountability and reasons for withdrawal}

Two hundred and twenty-six patients were screened, and 217 entered the study. Six patients had to be excluded from the analysis for various reasons (exclusion criteria (three), phimosis after laser therapy (one), two patients did not start treatment). Thus, 211 patients began the topical imiquimod 5\% treatment within 21 days of laser treatment of their external condylomata acuminata. Before entering the follow-up period, $73(34.6 \%)$ patients were withdrawn. The most common reasons for withdrawal were skin irritation $(n=18,8.5 \%)$, noncompliance $(n=16$, $7.6 \%)$ and wart recurrences $(n=15,7.1 \%)$. Twenty-seven of the remaining 138 patients were excluded during the six-month treatment-free follow-up period, mainly for noncompliance $(n=14,10.1 \%)$ and wart recurrence $(n=10$, 7.2\%). Overall, 111 patients (65 males, 67 females) completed the clinical trial.

Table I Previous treatments and patient experiences (patient questionnaire)

\begin{tabular}{|c|c|c|c|}
\hline Total number of patients & $\begin{array}{c}\text { Male }(\%) \\
(n=98)\end{array}$ & $\begin{array}{c}\text { Female (\%) } \\
\quad(n=1 \mid 3)\end{array}$ & $\begin{array}{l}\text { Total (\%) } \\
(n=2 \mathrm{II})\end{array}$ \\
\hline \multicolumn{4}{|l|}{ Previous treatments* } \\
\hline Patients & 58.2 & 48.7 & 53.1 \\
\hline Laser & 16.3 & 18.6 & 17.5 \\
\hline Podophyllin resin & 15.3 & 8.8 & 11.8 \\
\hline Podophyllotoxin & 13.3 & 9.7 & II.4 \\
\hline Electrocautery & 14.3 & 5.3 & 9.5 \\
\hline Cryotherapy & 3.1 & 1.8 & 2.4 \\
\hline Trichloracetic acid & I & 2.7 & 1.9 \\
\hline Liquid substances (not specified) & 3.1 & 6.2 & 4.7 \\
\hline Other & 2 & 0.9 & 1.4 \\
\hline \multicolumn{4}{|l|}{ *more than one answer possible } \\
\hline Wart recurrence & $35.1(n=20)$ & $43.6(n=24)$ & $39.3(n=44)$ \\
\hline within three month after treatment & 60 & 70.8 & 65.9 \\
\hline$>3$ months after treatment & 40 & 29.2 & 34.1 \\
\hline Pain & $37 / 53(69.8)$ & $42 / 52(80.8)$ & $79 / 105(75.2)$ \\
\hline Satisfaction & $(n=54)$ & $(n=53)$ & $(n=107)$ \\
\hline Very satisfied & 5.6 & I5. I & 10.3 \\
\hline Satisfied & 68.5 & 56.6 & 62.6 \\
\hline Not at all satisfied & 25.9 & 28.3 & 27.1 \\
\hline
\end{tabular}




\section{Sustained clearance: efficacy of imiquimod 5\% cream}

Sustained clearance was observed in 138/211 patients $(65.4 \%)$ until the end of the three-month treatment period with imiquimod $5 \%$ cream. Out of the 138 patients who entered the follow-up phase, $111(80.4 \%)$ showed sustained clearance at the end of the six-month treatment-free followup. A total of 25/211 patients, 15 during the treatment phase and ten during follow-up, developed recurrent warts in the ablated target wart areas from the start of the study until the end of the follow-up period, corresponding to $11.8 \%$ of all patients included in the study. Patients who were withdrawn prematurely for other reasons than recurrences $(n=55$ during the treatment phase, $n=20$ after the end of treatment) were not followed and therefore, sustained clearance could not be evaluated. Due to premature patient withdrawals, actual patient numbers were reduced from month to month (Table 2).
Removing patients lost to follow-up, 153 evaluable patients remained at the end of the three months of imiquimod treatment, 132 patients after the first three months of follow-up and 111 at the end of the six-month follow-up period; the incidences of recurrences related to the number of evaluable patients are $9.8 \%(n=15 / 153), 7.6 \%$ $(n=10 / 132)$ and $0 \%$, respectively. A stepwise analysis of observed clearance/recurrence rates, related to actual number of cases at the monthly control visits during treatment and every three months during follow up, revealed a consistently high percentage of patients who remained wart free for nine months after enrollment in the study (Figure 1); differences to $100 \%$ represent missing values. The highest number of recurrences (7.6\%), but also the highest percentage of patients with missing values (9.8\%), was observed during the first three months after the end of treatment. Overall, recurrence rates in male patients were slightly higher than in female patients. While on treatment

Table 2 Number of patients returned to monthly control visits during imiquimod 5\% treatment and treatment-free follow-up

\begin{tabular}{lccccc}
\hline & $\begin{array}{c}\text { Imiquimod } \\
\text { Baseline }(n=21 \mathrm{I})\end{array}$ & $\begin{array}{c}\text { Imiquimod } \\
8 \text { weeks }\end{array}$ & $\begin{array}{c}\text { Imiquimod } \\
12 \text { weeks }\end{array}$ & $\begin{array}{c}\text { Follow-up } \\
\text { months }\end{array}$ & $\begin{array}{c}\text { Follow-up } \\
6 \text { months }\end{array}$ \\
\hline Patients returned & 201 & 167 & 141 & 132 & 111 \\
males/females & $94 / 107$ & $78 / 89$ & $68 / 73$ & $65 / 67$ & $55 / 56$ \\
Patients withdrawn/lost to follow-up & 10 & 34 & 26 & 9 & 21 \\
\hline
\end{tabular}

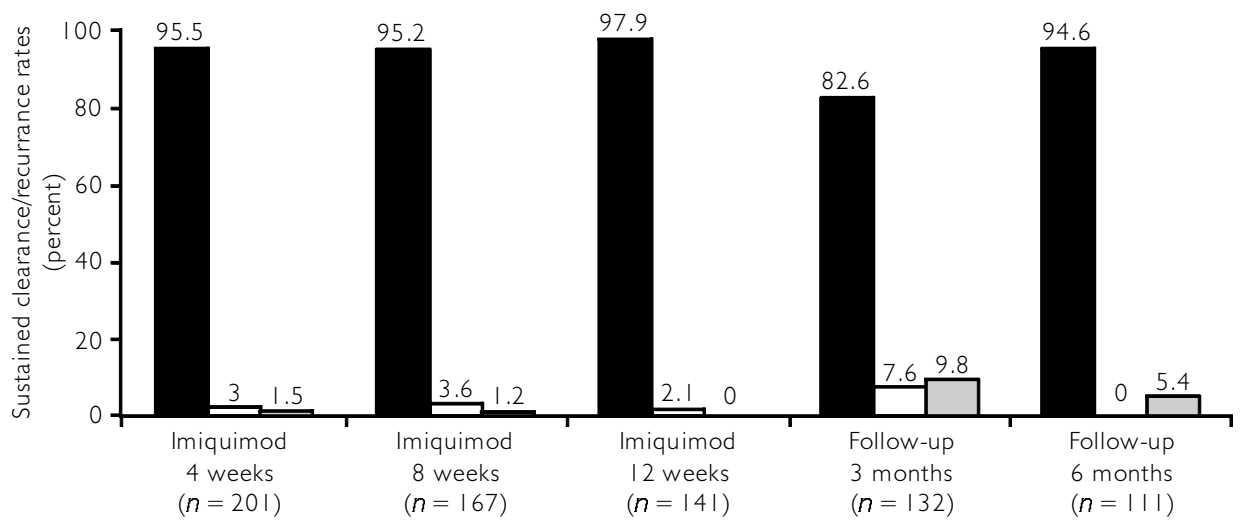

Figure I Percentage of observed sustained clearance $\square$ and recurrence $\square$ rates during imiquimod $5 \%$ cream

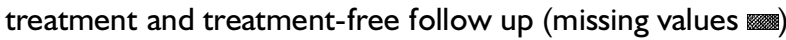


with imiquimod 5\% cream, 12\% (9/75) versus $7.7 \%(6 / 78)$ respectively presented recurrent warts in the target areas, during follow-up the corresponding percentages were $9.2 \%(6 / 65)$ and $6 \%$ (4/67).

New warts outside the treated areas were observed in 38/201 (18.9\%, 18 males, 20 females) patients during the treatment phase, and another 17/138 (12.3\%, 10 males, 7 females) patients developed new warts during the follow-up period.

\section{Compliance and patient questionnaire on adjuvant treatment with topical imiquimod}

There were only minor variations in the patient compliance rate during the three months of treatment $(83.6 \%, 79.6 \%$ and $88.7 \%$ in months one, two and three, respectively) without significant differences related to gender. Patients who successfully completed the three-month treatment $(n=138)$ were asked about their opinion on the use of adjuvant imiquimod 5\% cream. Overall, $89.1 \%$ of patients were 'very satisfied' or 'satisfied' with the treatment. Handling of the cream was judged as 'very easy' or 'easy' by $97.1 \%$. Most of the patients $(77.3 \%)$ did not lose any working or school days due to wart treatment. Details are given in Table 3.

\section{Safety evaluation}

No serious adverse events related to study drug were reported. Adverse events were most often related to local skin reactions at the treatment site, and in a few cases, systemic symptoms such as fever or myalgia were reported. Skin disorders in the treated wart areas including burning, itching, pain and redness were the most common adverse effects and occurred in more than $80 \%$ of all patients. Usually they were well tolerated and rapidly resolved after reduction of dosing or taking a rest period.

During the treatment phase, 18 patients $(8.5 \%)$ discontinued the study because of skin reactions at the application site. Most of them reported moderate to severe erythema, burning or pain and mild to moderate itching. Less frequently, other symptoms like edema, erosion, bleeding, scabbing, tickling or tenderness were observed. In two cases, patients developed systemic moderate to severe flu-like symptoms, which were judged by the investigators to be probably drug-related. One additional patient discontinued treatment prematurely because of fever, but had no other adverse events; in this case a causality to study drug could not be determined.

As expected, most of the patients (85.3\%) reported generally mild local skin reactions

Table 3 Results of patient questionnaire: end of three-month treatment with imiquimod $5 \% \mathrm{cream}$

\begin{tabular}{|c|c|c|c|}
\hline Question/statement & $\begin{array}{c}\text { Male }(\%) \\
(n=68)\end{array}$ & $\begin{array}{c}\text { Female (\%) } \\
(n=70)\end{array}$ & $\begin{array}{l}\text { Total }(\%) \\
(n=138)\end{array}$ \\
\hline \multicolumn{4}{|c|}{ Number of missed working/school days } \\
\hline 0 & $83.1 \%$ & $71.6 \%$ & $77.3 \%$ \\
\hline $\mathrm{I}-5$ & $7.4 \%$ & $12.9 \%$ & $10.2 \%$ \\
\hline $6-10$ & $1.5 \%$ & $2.9 \%$ & $2.2 \%$ \\
\hline $\mathrm{II}-28$ & $2.9 \%$ & $4.3 \%$ & $3.6 \%$ \\
\hline don't know/don't work & $4.5 \%$ & $7.1 \%$ & $5.8 \%$ \\
\hline missing values & $4.5 \%$ & $4.3 \%$ & $4.4 \%$ \\
\hline \multicolumn{4}{|l|}{ Ease of use } \\
\hline very easy & $66.2 \%$ & $51.4 \%$ & $58.7 \%$ \\
\hline easy & $29.4 \%$ & $47.2 \%$ & $38.4 \%$ \\
\hline difficult/very difficult & $4.5 \%$ & $1.4 \%$ & $2.9 \%$ \\
\hline \multicolumn{4}{|c|}{ Overall satisfaction with study drug } \\
\hline very satisfied & $32.4 \%$ & $20 \%$ & $26.1 \%$ \\
\hline satisfied & $55.9 \%$ & $70 \%$ & $63 \%$ \\
\hline not at all satisfied & $11.7 \%$ & $10 \%$ & $10.9 \%$ \\
\hline
\end{tabular}


Table 4 Frequency and severity of observed local skin reactions after laser treatment and during treatment with imiquimod $5 \%$ cream

\begin{tabular}{|c|c|c|c|c|c|}
\hline Symptom & Severity & $\begin{array}{c}\text { Post-laser (\%) } \\
(n=21 \mathrm{I})\end{array}$ & $\begin{array}{c}4 \text { weeks }(\%) \\
(n=20 I)\end{array}$ & $\begin{array}{c}8 \text { weeks }(\%) \\
(n=167)\end{array}$ & $\begin{array}{c}12 \text { weeks }(\%) \\
(n=141)\end{array}$ \\
\hline \multirow[t]{3}{*}{ Erythema } & mild & 49.8 & 35.8 & 45.5 & 39.7 \\
\hline & moderate & 10.4 & 25.9 & 19.2 & 17 \\
\hline & severe & 0 & 9.5 & 8.4 & 3.5 \\
\hline \multirow[t]{3}{*}{ Erosion } & mild & 37 & 20.9 & 21.6 & 15.6 \\
\hline & moderate & 17.1 & 9.5 & 6.6 & 5.7 \\
\hline & severe & 2.4 & 3 & 2.4 & 0.7 \\
\hline \multirow{3}{*}{ Edema } & mild & 22.7 & 14.9 & 14.9 & 15.6 \\
\hline & moderate & 0.9 & 8.5 & 8.5 & 0.7 \\
\hline & severe & 0 & 3.5 & 3.5 & 0.7 \\
\hline \multirow[t]{3}{*}{ Ulceration } & mild & 22.7 & 8.5 & 9.0 & $\mathrm{I} .4$ \\
\hline & moderate & 9 & 1.5 & 2.4 & 2.1 \\
\hline & severe & 0.9 & 2 & 0 & 0.7 \\
\hline \multirow[t]{3}{*}{ Vesicles } & mild & 0.5 & 0.5 & 2.4 & 0.7 \\
\hline & moderate & 0.5 & 0.5 & 1.2 & 0.7 \\
\hline & severe & 0 & 0 & 0 & 0 \\
\hline \multirow[t]{3}{*}{ Induration } & mild & 16.1 & 14.4 & 14.4 & 19.9 \\
\hline & moderate & 2.8 & 3 & 1.8 & 0.7 \\
\hline & severe & 0 & 0 & 0 & 0 \\
\hline \multirow[t]{3}{*}{ Excoriation/flaking } & mild & 5.7 & 6 & 8.4 & 8.5 \\
\hline & moderate & 4.3 & 6 & 4.8 & 2.8 \\
\hline & severe & 2.4 & 1 & 0 & 0.7 \\
\hline \multirow[t]{3}{*}{ Scabbing } & mild & 26.1 & 12.4 & 9 & 5 \\
\hline & moderate & 3.3 & 3.5 & 3 & 2.1 \\
\hline & severe & 0 & 0.5 & 0 & 0 \\
\hline
\end{tabular}

following laser therapy. After sufficient wound healing, patients started the imiquimod 5\% treatment. They were assessed monthly for specific local skin reactions known to be probably related to the study drug. During the whole treatment period, most patients did not present any objective skin reaction except for erythema, which was present in $60-70 \%$ of cases. Frequency and severity of symptoms was highest during the first month after laser treatment. In months two and three of treatment, the skin symptoms improved and the number of severe reactions decreased (Table 4). The most common application site reactions reported by the patients were itching/pruritus $(28.9 \%)$, burning $(20.9 \%)$ and pain (9\%). After the end of treatment, the local application site symptoms rapidly improved, and after six months only three patients $(2.7 \%)$ presented with mild erythema, induration or erosion.

\section{DISCUSSION}

Data in the literature show variable recurrence rates after laser therapy of genital warts, and recurrences develop most frequently in the margins of previously ablated areas. It has been postulated that the outcome could be improved by extending the ablation beyond the visible lesion to adjacent, clinically unaffected regions containing latent $\mathrm{HPV}^{4}$. However, neither microscopically guided treatment of acetowhite, subclinical HPV infection in males, nor $\mathrm{CO}_{2}$ laser vaporization of 
the entire inferior genital tract in females demonstrated eradication of the underlying viral infection or prevention of recurrences ${ }^{11,12}$. A different approach through the enhancement of the cutaneous antiviral immune response is available through immune response modifiers. The results of this open-label, prospective study demonstrate that the outcome of laser therapy for external genital warts can be sustained by an adjuvant topical immunomodulatory treatment, imiquimod 5\% cream. In this study, the results of laser therapy with imiquimod $5 \%$ cream were superior to those of laser therapy alone documented in the literature. Overall, $65.4 \%$ of all treated patients remained wart free after three months of active treatment, whereas only $7.1 \%(15 / 211)$ presented with wart recurrences during the treatment period. The remaining patients were lost to follow-up and their outcome is unknown. Furthermore, even the long-term results seem to be very promising with recurrences of $7.3 \%(10 / 138)$ during the first three months of treatment-free follow-up, and no further recurrences within the following three months. No effect was seen on the development of new warts in untreated skin areas observed in $27 \%(57 / 211)$ of patients; this is in accordance with animal studies which have shown that topical imiquimod exhibits its immunological effects exclusively at the application site ${ }^{13}$.

The reduced recurrence rate with adjuvant imiquimod 5\% cream treatment is likely to be related to the activation of a local cellular immune response, which is mediated largely through the induction of certain pro-inflammatory and antiviral cytokines, predominantly IFN- $\alpha$, tumor necrosis factor- $\alpha$ (TNF- $\alpha$ ) and several interleukines (e.g. IL-6, -8, -10, -12). The mechanism of action in HPV-related genital warts has been demonstrated in a molecular study with HPVinfected patients ${ }^{7}$. Regression of warts was directly related to changes in the tissue levels of these cytokines and a significant reduction in viral load as measured by tissue levels of E7-mRNA and capsid protein L1-mRNA. Most interestingly, one of the study subjects treated with placebo also experienced complete clearance of his warts, and the changes in immunological markers documented in this subject were very similar to those in the imiquimod-treated patients. This enhancement of the local immune response also results in a long-term effect on dermal HPV-infections, with prevention of recurrences and new infections with the same HPV type or subtype, comparable to the immunological process occurring during spontaneous regression ${ }^{14}$.

From previous studies it is known that local skin reactions occur frequently, especially during the first month of treatment with imiquimod 5\% cream and are considered to be due to the local immune induction and are an essential aspect of the drug's antiviral and antitumor activity ${ }^{7-9}$. In this study, imiquimod 5\% cream was applied following laser therapy and the incidence of skin reactions was highest during the first month of treatment. Wound healing itself is associated with specific alterations in skin immunology. It has been demonstrated that during 42 days after surgery there is a decrease of total T-lymphocytes in the margins of dermal wounds, associated with an increase in $\mathrm{CD}^{+} \mathrm{T}$-suppressor cells and a reduction of the $\mathrm{CD}^{+} / \mathrm{CD} 8^{+} \mathrm{T}$-lymphocyte ratio, and a concomitant increase in B-lymphocytes ${ }^{15}$. The pattern of cytokines evaluated in surgical wounds, and after thermal injury, revealed elevated local concentrations of transforming growth factor- $\beta$ (TGF-B) and pro-inflammatory cytokines like IL-1, IL-6, IL-8 and TNF- $\alpha^{16-18}$. The concentrations of the single cytokines varied according to different steps of wound healing during the observation periods. However, no long-term studies have been performed, and the cytokine kinetics or activity of macrophages two or three weeks after a thermal injury are still undetermined.

Provided that early inflammation is an important factor in any kind of wound healing, including thermal injury by laser treatment, it was not surprising to observe an enhanced incidence of local skin reactions to post-laser therapy with imiquimod 5\% cream which also induces the expression of certain pro-inflammatory cytokines. The most frequently reported skin reaction was erythema in approximately $40 \%$ of all patients, with severe erythema in approximately $10 \%$ of patients. This is comparable to previous results with imiquimod 5\% cream for primary treatment of external genital warts in uncircumcised males 9 . Edema, excoriation/flaking and scabbing were somewhat more pronounced in laser treated 
patients. However, in the third month of adjuvant imiquimod therapy the incidence of skin reactions generally returned to levels reported from other studies. This indicates that adjuvant treatment with imiquimod 5\% cream following ablative therapy should not start unless the wound healing is apparently completed.

Patients who remained in the study during the complete treatment course generally were very satisfied with the combined ablative/adjuvant treatment. This probably is related to the low recurrence rate compared to previous experiences, better tolerability and simple, self-administered drug treatment. On the other side, the high drop out rate is one of the major critical issues of this study and is most likely due to patients' reluctance to follow a three months medical treatment course after complete ablation of their lesions with no clinically visible genital warts. To ensure patients benefit from the therapeutic procedure, they should be instructed thoroughly on adherence to the proposed treatment schedule and administration of the drug only to the area involved, including the margins of the ablated area.

The data presented in this study clearly demonstrate that laser treatment of genital warts followed by treatment with topical imiquimod 5\% cream over 12 weeks is safe and appears to be an effective therapeutic approach to reduce the incidence of wart recurrences, one of the most unsatisfactory aspects of conventional treatment modalities.

\section{ACKNOWLEDGEMENTS}

This study was funded by $3 \mathrm{M}$ Medica, Borken, Germany. The authors would like to gratefully acknowledge the contribution of the investigators participating in the study: Departments of Dermatology (Prof. Dr. G. Albrecht, Berlin; Prof. Dr. P. Altmeyer, Bochum; Prof. Dr. E.-B. Bröker, Würzburg; Prof. Dr. E. Christophers, Kiel; Prof. Dr. C. Garbe, Tübingen, Prof. Dr. U.-F. Haustein, Leipzig; Prof. Dr. A. Kapp, Hannover; Prof. Dr. S. W. Wassilew, Krefeld; Prof. Dr. V. Wienert, Aachen), Departments of Obstetrics and Gynecology (Dr. A. Ahr, Frankfurt; Prof. Dr. W. Albrich, Munich; Prof. Dr. K. Friese, Rostock; PD Dr. H. Ikenberg, Freiburg; Prof. Dr. F. Jänike, Hamburg; Dr. P. Hillemanns, Munich; Prof. Dr. F. Melchert, Mannheim; Dr. K.-U. Petry, Hannover), Department of Urology (Dr. P. Derakhshani, Cologne), and Center of Laser Therapy (Prof. Dr. H.-P. Berlien, Berlin).

\section{REFERENCES}

1. Koutsky L. Epidemiology of genital papillomavirus infection. Am J Med 1997;102(5A):3-8

2. von Krogh G, Lacey CJN, Gross G, et al. European course on HPV associated pathology: guidelines for primary care physicians for the diagnosis and management of anogenital warts. Sex Transm Infect 2000;76:162-8

3. Beutner KR, Wiley DJ. Recurrent external genital warts: A literature review. Papillomavirus Report 1997;8:69-74

4. Ferenczy A, Mitao M, Nagai N, et al. Latent papillomavirus and recurrent genital warts. NEnglJ Med 1985;313:784-8

5. Miller RL, Gerster JF, Owens ML, et al. Imiquimod applied topically: a novel immune response modifier and new class of drug. Review article. Int J Immunopharmacol 1999;21:1-14

6. Stanley MA. Mechanism of action of imiquimod. Papillomavirus Report 1999;10:23-9
7. Tyring SK, Arany I, Stanley MA, et al. A randomized, controlled, molecular study of condylomata acuminata clearance during treatment with imiquimod. J Infect Dis 1998;178:551-5

8. Edwards L, Ferenzcy A, Baker D, et al. Selfadministered topical 5\% imiquimod cream for external genital warts. Arch Dermatol 1998;134: 25-30

9. Gollnick H, Barrasso R, Jappe U, et al. Safety and efficacy of imiquimod $5 \%$ cream in the treatment of penile genital warts in uncircumcised men when applied three times weekly or once per day. Int $J$ STD AIDS 2001;12:22-8

10. Czelusta AJ, Evans T, Arany I, Tyring SK. A guide to immunotherapy of genital warts - focus on interferon and imiquimod. BioDrugs 1999;11: 319-32

11. Carpinello VL, Zderic SA, Malloy TR, Sedlacek T. Carbon dioxide laser therapy of subclinical 
condyloma found by magnified penile surface scanning. Urology 1987;29:608-10

12. Riva JM, Sedlacek T, Cunnane MF, Mangan CE. Extended carbon dioxide laser vaporization in the treatment of subclinical papillomavirus infection of the lower genital tract. Obstet Gynecol 1989;73: 25-30

13. Imbertson LM, Beaurline JM, Couture AM, et al. Cytokine induction in hairless mouse and rat skin after topical application of the immune response modifiers imiquimod and S-28463. J Invest Dermatol 1998;110:743-39

14. Coleman N, Birley HDL, Renton AM, et al. Immunological events in regressing genital warts. Am J Clin Pathol 1994;102:768-74

ReCEIVED 06/11/01; ACCEPTED 12/10/01
15. Boyce DE, Jones WD, Ruge F, et al. The role of lymphocytes in dermal wound healing. $\mathrm{Br} J$ Dermatol 2000;143:59-65

16. Holzheimer RG, Steinmetz W-G. Local and systemic concentrations of pro- and antiinflammatory cytokines in human wounds. Eur J Med Res 2000;5:347-55

17. Kawakami M, Kaneko N, Anada H, et al. Measurement of interleukin-6, interleukin-10 and tumor necrosis factor- $\alpha$ levels in tissues and plasma after thermal injury in mice. Surgery 1997;121:440-8

18. Ravage ZB, Gomez HF, Czermak BJ, et al. Mediators of microvascular injury in dermal burn wounds. Inflammation 1998;22:619-29 


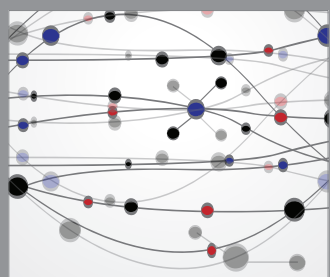

The Scientific World Journal
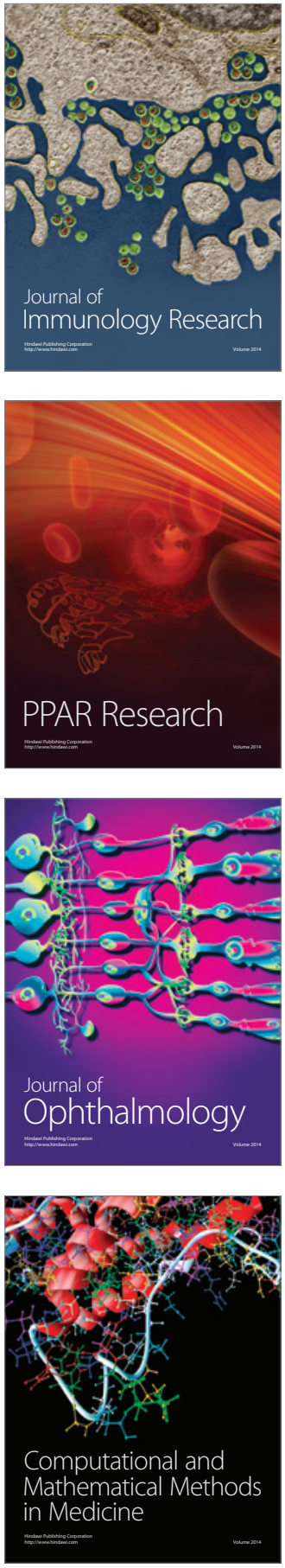

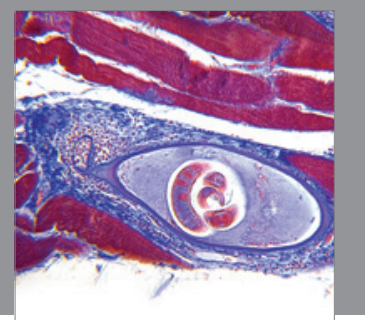

Gastroenterology

Research and Practice
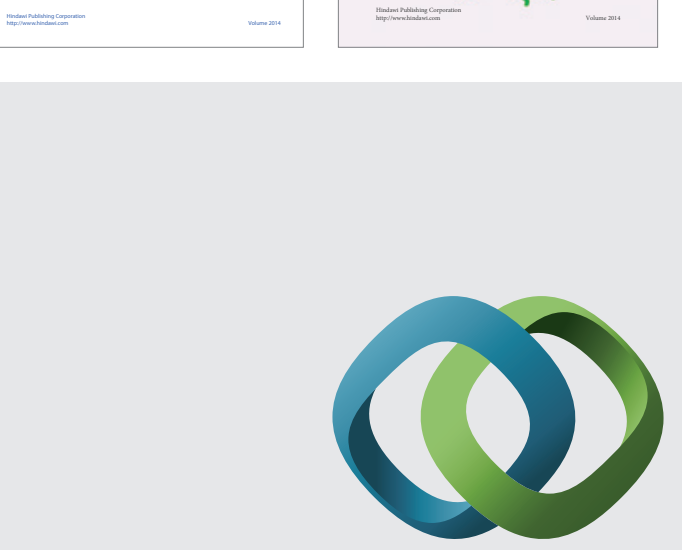

\section{Hindawi}

Submit your manuscripts at

http://www.hindawi.com
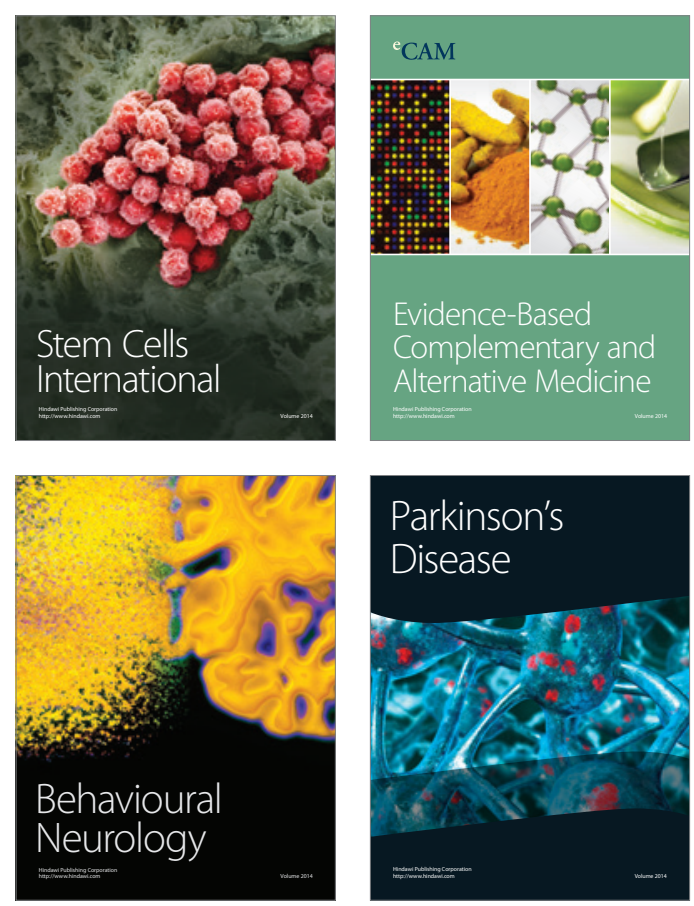

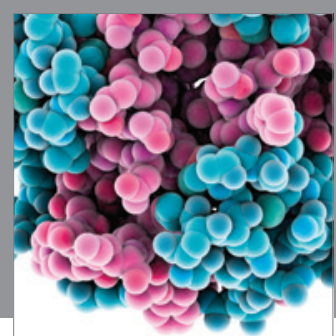

Journal of
Diabetes Research

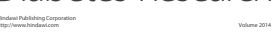

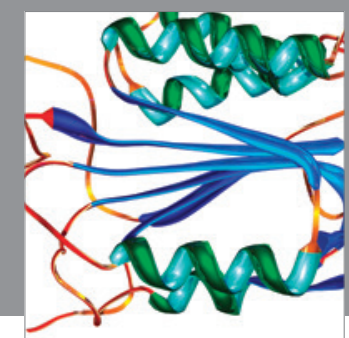

Disease Markers
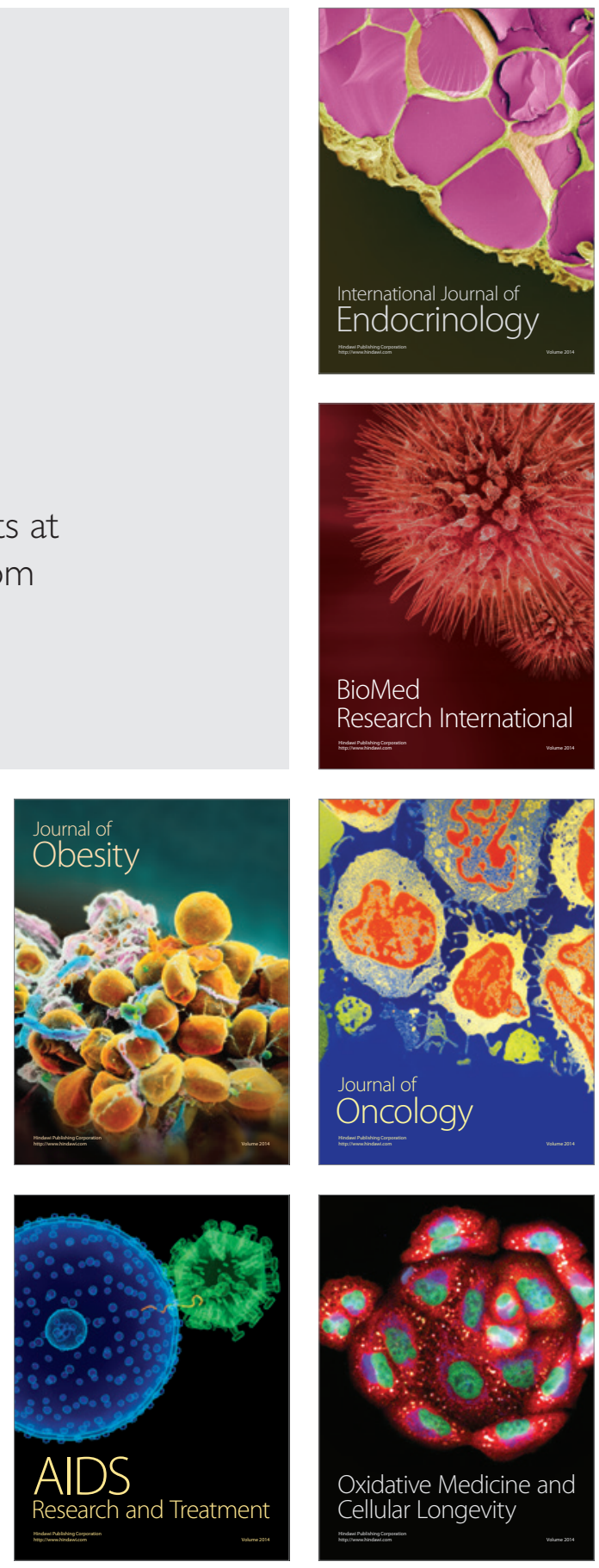